\title{
Padrões Tipológicos da Função Interpessoal Modalidade em Artigos Científicos de Ciências Agrárias: Diferenças e Similitudes entre Português e Inglês Typological Patterns across the Interpersonal Metafuntion Modality in Agricultural Scientific Articles: Differences and Similarities both in Portuguese and English
}

\author{
Tania Regina de Souza Romero
}

(UFLA)

Norma Lírio de Leão Joseph

(UFLA)

\section{RESUMO}

Pautando-se pelo propósito de subsidiar o ensino de inglês para fins acadêmicos para pós-graduandos de ciências agrárias, as autoras identificam padrões tipológicos de modalidade entre o inglês e o português brasileiro, especificamente em artigos científicos de ciências agrárias. Os artigos são processados no software AntConc 3.2.1w para identificação de estruturas modalizadas. Em seguida, categoriza-se os itens foco para que, então, se contraste o uso e frequência em uma língua e outra. Os resultados mostram uma grande convergência de uso, o que indica a possibilidade de abordagens de ensino baseadas em familiaridade com o gênero. Concluindo, as autoras refletem sobre a contribuição da Linguística Sistêmico-Funcional ao ensino-aprendizagem de inglês como língua estrangeira no contexto acadêmico.

Palavras-chave: modalidade - artigos cientificos - ciências agrárias português e inglês. 


\section{ABSTRACT}

The purpose of this investigation is identifying typological patterns of modality present in Brazilian Portuguese and English, specifically in scientific articles in the area of agricultural sciences. This would contribute to the teaching of English for Academic Purposes for graduate students of agricultural sciences. Thus, the authors compare scientific articles both in Portuguese and in English to observe the use of modal patterns. The computational tool AntConc 3.2.1w enables us to both identify and categorize the modalized structures so that use and frequency can be contrasted. The results unveil a strong convergence of use, which envisions the possibility of teaching approaches in the foreign language based on the familiarity with the genre. In conclusion, the authors reflect on the contribution of Systemic Functional Linguistics to the teaching and learning of English in academic context.

Key-words: Modality - Scientific Articles - Agricultural Sciences Portuguese and English.

What can the language educator do to help those who have been shut out of scientific discourse? The language educator can only help the learner if (s)he understands how the discourse works (J. J. Webster, 2007:xvi)

\section{Introdução}

A epígrafe acima claramente explicita a responsabilidade do educador de línguas ante o ensino-aprendizagem de gêneros próprios do contexto científico. Essa responsabilidade vai além de simplesmente se conhecer teoricamente a disciplina que se ensina, comum a tantas. Também abrange, especialmente no caso de língua estrangeira, conhecer seus alcances, significados e usos em contextos específicos. Ressalte-se, ademais, o subjacente valor social e emancipatório para o estudante quando passa a entender e fazer uso desses significados no meio científico, pois que, assim, potencialmente obtém ingresso ao cobiçado e hermético meio acadêmico. A habilidade de compreensão desse específico discurso, portanto, como acentua a citação acima, age como um instrumento de inclusão no mundo da ciência. 
Ao apresentar a edição chinesa das considerações de Halliday sobre as características distintivas da linguagem da ciência, o editor Webster, além de trazer a provocação que abre essa contribuição, lembra que o principal fundador da perspectiva sistemicista iniciou sua carreira lecionando inglês como língua estrangeira, o que, aliado a sua formação lingüística, deduzimos ter contribuído para o estabelecimento das bases para as novas concepções estudo e compreensão de linguagem que se seguiram. Dentre essas bases, a crucial, a nosso ver, é a função de construir significados e, por conseguinte, tecer interação, moldar o entendimento de mundo, elaborar formas de se edificar desenvolvimentos - elementos sem os quais não se faz ciência.

O preparo do educador de línguas para lidar com o desafio que se apresenta e as respectivas implicações que daí decorrem, entretanto, não tem sido suficiente, segundo Gebhard (2010:797):

(...) many teachers have had little or no preparation for providing the assistance that second language learners need to understand how academic language works in the types of texts they are routinely required to read and write in school (Hyland, 2003; Martin \& Rose, 2003, 2008; Schleppegrell, 2004). This lack of attention to how academic English works in disciplinary texts has contributed to the persistent achievement gap between majority and minority students (...)

Marcantes esforços para suprir essa necessidade têm sido empreendidos pelo grupo SAL (Systemics Across Languages), notadamente em seu ramo sulamericano que, sob a liderança de Barbara, vem se debruçando sobre o discurso científico. De modo similar e igualmente tendo como fundamento orientador a Linguística Sistêmico-Funcional (LSF), estudos com base em gêneros visando o ensino-aprendizagem de discursos de disciplinas específicas vêm sendo desenvolvidos na Escandinávia e em países de língua inglesa, como a Inglaterra, Austrália e Estados Unidos (cf.: Montemayor-Borsinger 2009). O enfoque nesses estudos, informa a autora, é a observação de diferentes formas de se construir sentidos por meio da gramática em discursos de áreas específicas, considerando-se opções diferentes oferecidas pelo sistema de linguagem.

Ademais, outros estudos tem refletido sobre a acentuada relevância da LSF na educação, bem como tornado mais robusta uma produção 
consistente com as situações e visões construídas em português-brasileiro, como, dentre tantos mais, as elaborações de Ninin e Romero (2008), Vian Jr. e Souza e Almeida (2011), Vian Jr. e Ikeda (2009).

Explicitando nosso contexto propriamente dito, pode-se observar uma similaridade de propósitos. Atuamos em uma universidade que, por contar com sólida presença na produção científica brasileira na área de ciências agrárias, prima por investir no desenvolvimento de seus pósgraduandos. Para tanto, uma das iniciativas é incluir tanto no programa dos cursos de graduação quanto de pós-graduação aulas de inglês instrumental, visando otimizar o acesso a literaturas das áreas afins.

De nosso ponto de vista como professoras, entretanto, há que se considerar que, embora tenhamos familiaridade com a linguagem acadêmica e experiência com a abordagem instrumental, a área de ciências agrárias ainda nos era desconhecida. Essa lacuna indicou-nos a necessidade de investigarmos o discurso e - especificamente nesse artigo- algumas realizações gramaticais dos artigos dessa área de conhecimento. Pareceu-nos plausível, concordando com observações de Thompson (2009, comunicação pessoal), haver distinções expressas na tessitura dos discursos de nossa ciência, lingüística aplicada, e da ciência alvo.

Sendo assim, com o intuito de contribuir para o ensino-aprendizagem de leitura e escrita de textos acadêmicos para graduandos e pós-graduandos, lançamo-nos a estudar artigos de ciências agrárias publicados em português e inglês para: (a) identificar as diferentes estruturas modalizadas e operadores modais usados nos artigos científicos de ciências agrárias para expressar diferentes atitudes e julgamentos; (b) categorizá-los e (c) classificá-los hierarquicamente segundo a freqüência de uso.

Este artigo, portanto, distingue-se dos demais por apoiar-se nas ferramentas disponibilizadas pela LSF para fazer uma comparação de uso de modais dentro do mesmo gênero entre o português, que é a língua mãe tanto das professoras quanto dos estudantes foco, e o inglês, a língua em que a ciência é mais difundida no mundo atualmente.

Considerando-se que este trabalho compara realizações lingüísticas em um mesmo gênero, mas em dois idiomas distintos, pode-se defini- 
lo como um estudo tipológico (cf.: Caffarel, Martin e Matthiessen 2004). Um estudo tipológico, portanto, inclui as abordagens teórica e metodológica para que se possa traçar um mapeamento com padrões lingüísticos presentes ou ausentes nas línguas em questão. Dessa forma, possibilita-se que uma ou mais línguas sejam descritas. A partir das descrições percebidas pode-se chegar a generalizações tipológicas, ou seja, obtém-se padrões de semelhanças e diferenças presentes nas línguas comparadas, o que produz recursos e/ou meios para que se distingua possibilidades gramaticais nos sistemas em análise.

\section{Base teórica}

Retomando o já mencionado, o significado de textos é central para a LSF. Os significados embrenhados na linguagem são construídos e constroem cultura por meio de um sistema de escolhas semânticas, gramaticais e textuais realizadas oralmente ou por escrito por pessoas inseridas em contextos reais específicos, visando objetivos também específicos. Nessa conceituação, entende-se que a linguagem é social e indissociável da experiência humana.

Um importante traço distintivo da LSF, a partir das elaborações originais de Halliday (1994), é a visão que textos comportam concomitantemente três significados diferentes: ideacionais, interpessoais e textuais. Os ideacionais referem-se a como a realidade, o mundo é experienciado. Os interpessoais indicam como as relações sociais se realizam. E os textuais organizam os outros significados de forma coerente. Cada um desses significados dá origem a um enfoque gramatical próprio, ou metafunção.

Sendo nosso propósito discutir a modalidade, iniciemos por pontuar que esta se inclui na metafunção interpessoal. Thompson (1996) simplifica o entendimento do termo explicitando que modalidade é o espaço entre o "sim” e o "não". Para Eggins (1994), esse é um recurso de que dispõe o usuário da linguagem para expressar seus julgamentos e atitudes.

Cabe comentar que na Linguística Aplicada é praticamente comum ao pesquisador fazer uso da primeira pessoa e assumir interpretações e conclusões de suas investigações quase sempre fundadas em 
pesquisas qualitativas e interpretativas. Tal característica, portanto, pode explicar ser a ocorrência de modalidade bastante comum. Nas ciências agrárias, por outro lado, há um distanciamento do pesquisador do objeto pesquisado, sendo raro o uso da primeira pessoa e costume a pesquisa quantitativa, visando resultados claros e observáveis. Isso nos fez hipotetizar menor uso de modalidade. Não chegamos ainda, todavia, a comparar artigos científicos em Linguística Aplicada e Ciências Agrárias.

Halliday (1994) subdividiu a modalidade em modalização e modulação. A modalização refere-se à validade da informação, ou seja, permite ao falante ou escritor expressar seu nível de certeza, probabilidade ou freqüência de algo que está acontecendo ou é. Já a modulação remete a graus de obrigação de se atender um comando ou inclinação e disposição de alguém em fazer uma oferta.

Gramaticalmente, a modalidade é realizada na linguagem implicitamente por meio de: (a) operadores modais (por exemplo: Esse problema poderá ocorrer); (b) adjunto de modo (como em: Esse problema possivelmente ocorrerá), ou (c) por meio de operador modal e adjunto de modo (exemplo: Esse problema possivelmente poderá ocorrer). Explicitamente, ou seja, quando o falante ou escritor assume diretamente a responsabilidade, ocorre uma metáfora de modalidade (no caso de: Eu acho que o problema ocorrerá).

A colocação dos operadores modais tende a ser antes do verbo no infinitivo e expressa significados variados de certeza ou obrigação. Para ilustrar, comparemos as sentenças: Uma erosão pode acontecer e Uma erosão deve ocorrer.

Com adjuntos modais são expressas atitudes. Há quatro tipos de adjuntos modais na classificação de Halliday: adjuntos de modo, de polaridade, de comentário e vocativos. Considerando-se sua posição gramatical na frase, os dois primeiros relacionam-se diretamente a significados interpessoais, estando, evidentemente, os de polaridade no espaço entre "sim" e "não" e demais alternativas próprias da conversação. Os adjuntos de modo possibilitam uma outra alternativa para a expressão de opinião (cf.: Eggins 1994), tendo cinco categorizações em inglês. Há evidências em trabalhos publicados em língua portuguesa (cf.: Romero 2004, Ninin e Romero 2008) que indicam que a 
mesma categorização se aplica à língua: (a) probabilidade (talvez, provavelmente, possivelmente etc), (b) freqüência (às vezes, geralmente, sempre, nunca etc), (c) intensificação ou minimização (realmente, somente, um pouco, simplesmente etc), (d) presunção (evidentemente, obviamente, claramente, sem dúvida etc) e (e) inclinação (felizmente, infelizmente etc).

A metáfora de modalidade é assim chamada por estar gramaticalmente em uma oração separada e completa, como em Eu acho, Temos certeza. Com ela fica explícita a autoria ou fonte da modalidade, uma vez que o pronome ou participante se evidencia. Por outro lado, é possível se conferir uma característica impessoal, mascarando-se o julgamento com recursos como É possível que... É certo que... Essas estruturas dão uma ideia objetiva, apesar de se referir a uma avaliação pessoal (cf.: Thompson 1996).

É relevante frisar que o uso da modalidade aponta maior ou menor grau de certeza sobre a validade da proposição ou de pressão sobre o ouvinte/leitor em decorrência de um comando. Isso fica claro ao se modificar somente o operador modal em asserções similares, como por exemplo: Pode-se optar pela inseminação / Deve-se optar pela inseminação. O "pode" remete a um valor baixo de modalidade, significando permissão, já o "deve", significando obrigação, tem valor mais alto. A diferença entre uma escolha e outra expressa maior ou menor comprometimento ou responsabilidade do falante/escritor quanto ao que é tratado.

O uso de modalidade é capital para se ter acesso ao posicionamento do autor ou falante. Por essa razão, lembremos a importante observação de Eggins (1994:182): Quanto mais se diz que algo é certo, menos certo é. Se temos certeza de algo, não usamos modalidade.

Partindo das formulações de Halliday sobre os significados inerentes ao sistema de modalidade, Martin e White (2005) desenvolveram posteriormente tipologias gramaticais referentes a julgamentos engajamento que acrescentam e aprofundam os recursos linguísticos disponíveis para a compreensão de textos escritos e orais.

Nossas discussões nesse artigo restringem-se ao sistema de modalidade hallidayanas originais, ou seja, o âmbito tipológico foco é a 
realização de modalidade em inglês e português brasileiro no gênero artigos científicos na área de ciências agrárias. Tal escolha de análise relaciona-se ao significado de possibilidades e permissão que o sistema constrói - o que é especialmente relevante em textos científicos da área foco, pois, através deste recurso linguístico, se indica gamas de opções, capacidades e probabilidades de interpretação no fazer e inferir em ciências agrárias.

\section{Metodologia}

Insere-se esta pesquisa em um projeto interinstitucional e internacional denominado SAL (Systemics Across Languages), tendo como base a teoria de gêneros textuais (Christie 2005, Martin e Rose 2005), a análise do discurso de base sistêmico-funcional (Halliday 2004, Halliday e Mathiessen 2004). O projeto SAL mundial investiga vários gêneros diferentes. Esse trabalho, a exemplo de outros desenvolvidos por pesquisadores sistemicistas na América do Sul, como o de Barbara e Macêdo (2011), por exemplo, ocupa-se especificamente de artigos científicos. Enquanto o de nossas colegas comparou português e espanhol, o nosso compara português e inglês.

Para o presente estudo, propusemo-nos a mapear a marca linguística modalidade a fim de darmos continuidade à investigação que estamos desenvolvendo dentro de nosso projeto maior registrado no CNPq que visa caracterizar principais traços linguísticos de artigos científicos na área de ciências agrárias. Dessa forma, estamos delineando tipologias lingüísticas inter-línguas na função interpessoal, particularmente na modalidade.

Compartilhando do banco de dados do grupo SAL brasileiro que inclui artigos científicos de várias áreas, tomamos os da área de ciências agrárias em português. Esses são provenientes da base Scielo Brasil (www.scielo.org). Para a seleção dos artigos da mesma área em língua inglesa consideramos apenas os produzidos originalmente em inglês e por autores nativos. Todos são originários do portal Science Direct (www.sciencedirect.com). Assim, nosso corpus é composto de 223 textos escritos em português e 150 escritos em inglês. O corpus de língua portuguesa conta com 661.930 palavras ou 36.650 tipos de 
palavras diferentes. O corpus em inglês totaliza 725.495 palavras, ou 28.175 tipos de palavras.

Para organização e tratamento dos dados, utilizamos a ferramenta computacional AntConc 3.2.1w (http://www.antlab.sci.waseda.ac.jp/ antconcindex.html), disponibilizado gratuitamente na internet para que as palavras foco se evidenciassem. Após a localização dessas palavras pela ferramenta, a interpretação do significado para, por exemplo, se poder diferenciar entre pode/can como probabilidade ou capacidade foi feita pela pesquisadoras, com base nas colocações linguísticas e contexto maior. Identificados, esses itens, em ambas as línguas, foram divididos em quatro categorias: (a) operadores modais, (b) adjunto de modo, (c) adjunto de comentário e (d) metáfora de modalidade. $\mathrm{O}$ próximo passo foi classificar todos os itens segundo a frequência de uso por língua. A seguir, foi feita a comparação de cada item em cada uma das línguas para se verificar a tendência de realização, como se verá a seguir.

\section{Análise dos dados}

Halliday (2004:116) afirma que modalidade significa que uma proposição é provável ou improvável e uma proposta é atraente ou indesejável. Dessa forma, tanto a proposição quanto a proposta são avaliadas em termos do grau de probabilidade ou obrigação associado a elas. Abordando modalização e modulação, o autor supracitado complementa que modalidade como um caso de dêixis interpessoal constrói uma região de incerteza onde o falante/escritor/ouvinte/leitor expressa ou pede a alguém para emitir uma avaliação sobre a validade do seu enunciado.

Prosseguiremos, agora, analisando as categorias identificadas nos corpora: (a) operadores modais, (b) adjunto de modo, (c) adjunto de comentário e (d) metáfora de modalidade, levando em consideração o que Halliday (2004:150) nos diz que "diferenças em significado podem obter um efeito marcado no desdobramento e impacto do discurso".

O operador modal como a primeira categoria a ser estudada, revela-nos uma maior frequência (1008 ocorrências de pode, pode ser, pode-se e poderia) em português e (2677 ocorrências de can e may) 
em inglês. Já nesse momento de nossa investigação, que é o início, há evidência de que os operadores modais de modalização superam em uso e frequência os de modulação (deve, deve-se, ter que; must, should) de baixa ocorrência ( $20 \%$ e $15 \%)$ em ambas as línguas. Observamos, aqui, que os dados corroboram em ressaltar que o recurso linguístico modalização coaduna com o propósito comunicativo dos artigos científicos da área que é, prioritariamente, oferecer opções de técnicas e avanços tecnológicos aplicados em ciências agrárias.

A tabela com a frequência dos operadores modais abaixo especifica numericamente as encontradas nos artigos em português e inglês.

\section{Tabela 1: Operadores modais}

\begin{tabular}{|c|c|c|}
\hline Modalização & Ocorrências & $\%$ \\
\hline pode + inf / may & $455 / 1341$ & \\
\hline pode ser / can & $375 / 1336$ & \\
\hline pode-se & $124 / 0$ & \\
\hline poderia & $54 / 0$ & \\
\hline Total & 1008 / 2677 & $80 \% / 85 \%$ \\
\hline Modulação & Ocorrências & $\%$ \\
\hline deve + inf / should & 170 / 347 & \\
\hline deve-se/ must & $65 / 126$ & \\
\hline ter que & $8 / 0$ & \\
\hline Total & $243 / 473$ & $20 \% / 15 \%$ \\
\hline
\end{tabular}

Considerando que a maior incidência em ambas as línguas foi a do operador modal poder + infinitivo, podemos verificar nos excertos abaixo que o escritor estabelece uma marca no seu enunciado de possibilidade que é expressa por proposições contingentes, isto é, que dependem de como o mundo é. O conhecimento do escritor sobre o mundo é representável como um conjunto de proposições (pode acarretar, pode aumentar, pode alterar). Assim sendo, uma proposição é possível se for compatível com aquilo que o escritor sabe sobre o mundo. 
Baixa disponibilidade de $\mathrm{P}$ pode acarretar maior efeito benéfico da micorrização ao café (Saggin-Junior e Siqueira, 1996), que com alta disponibilidade, a resposta à simbiose é mínima (Tristão et al., 2003). Este é um fator importante para a produção de mudas em substratos comerciais, pois são geralmente pobres em nutrientes, havendo necessidade de emprego de fertilizantes, o que encarece o produto. Nesse aspecto, a utilização de fungos micorrízicos eficientes é uma possibilidade interessante, pois pode aumentar a eficiência na utilização dos fertilizantes, diminuindo a quantidade necessária para garantir o adequado desenvolvimento da muda de café.

Certamente, os valores de período mínimo de colheitas não devem ser os mesmos para todas as condições. O coeficiente de repetibilidade é uma relação entre as variâncias genética e ambiental (Cruz e Regazzi, 1997) e qualquer grande alteração ambiental, local e época de cultivo, por exemplo, pode alterar a estimativa da repetibilidade.

Com significado similar, mas realização na voz passiva, encontramos um alto número de ocorrências (375 em português) no formato poder ser + particípio passado. O significado aqui construído leva-nos a entender que as proposições constituem a qualificação do escritor sobre certo estado de coisas (pode ser praticado, pode ser atribuída) em termos das chances de que esses fatos ocorram em algum mundo provável.

Apesar de o controle químico oferecer certas vantagens sobre os demais métodos de controle de plantas daninhas, deve-se ressaltar que este só pode ser praticado com o uso de herbicidas seletivos para a cultura. Segundo Velini et al. (2000), para ser recomendado de forma definitiva e indiscriminada para uma determinada cultura, um herbicida deve demonstrar seletividade aos cultivares mais comuns dessa cultura.

Em Três Pontas, a produtividade média foi de 31,41 sc ha-1 enquanto em São Sebastião do Paraíso foi de 22,13 sc ha-1. A maior produtividade das progênies em Três Pontas pode ser atribuída ao sistema de plantio adotado uma vez que o espaçamento foi de 2,5 x 0,70 m (5.714 plantas/ha), o qual corresponde ao sistema adensado.

Ademais, o operador modal pode-se + infinitivo (124 ocorrências em português) além de atribuir uma qualificação sobre a probabilidade de o conteúdo de uma proposição ser ou poder ser validado, torna evidente, através da partícula se, de indeterminação do sujeito, 
que o escritor se exime da responsabilidade da proposição (pode-se inferir, pode-se assegurar), utilizando uma formulação sem nenhuma orientação atitudinal explícita sobre o agente da proposição (Martin e White 2005).

Em uma situação de deficiência de potássio, seria esperado efeito da aplicação do nutriente sobre características de fibra como uniformidade de comprimento, comprimento e micronaire (Cassman et al., 1990; Pettigrew e Meredith, 1997). Como não houve efeito significativo dos tratamentos, pode-se inferir que não faltou potássio para o desenvolvimento das fibras.

Com esses resultados pode-se assegurar qual o melhor momento para a realização de uma liberação, a fim de que o crisofíceo se adapte às condições ambientais desfavoráveis sem afetar sua eficiência no controle de pragas.

No entanto, o operador modal poderia + infinitivo (54 ocorrências em português) permeia o discurso com enunciados que revela a existência de um tempo irreal, i.e., as proposições são fracamente asseveradas como prováveis. Quando o escritor diz poderia causar/ poderia parecer, ele condiciona a sua proposição uma relação semântica hipotética.

Ajustou-se o pH final para 4,0, com uma solução de H2SO40,5 mol L-1, evitando-se adicionar $\mathrm{NaOH}$, que poderia causar a precipitação do alumínio, pelo menos no local da queda da gota. As plantas ficaram crescendo por 48 horas nas soluções de tratamento, quando foram transferidas novamente para as soluções nutritivas completas onde as plântulas cresceram nas primeiras 48 horas.

$\mathrm{Na}$ ausência de braquiária, observou-se que a eficiência média dos fertilizantes nitrogenados foi de $51,6 \%$ do $\mathrm{N}$ aplicado, sendo inferior, em média, $9,1 \%$ em relação à quantificada na presença da braquiária, o que poderia parecer contrário ao esperado. Com o cultivo do milho em consórcio não foi afetada negativamente a assimilação de $\mathrm{N}$-fertilizante, e sim atuação de forma sinérgica, o que é merecedor de estudos na rizosfera para maior compreensão desse processo.

Toda essa complexidade se reflete, na prática, na outra língua, o inglês, no fato de que os operadores modais may + infinitivo (1341 ocorrências) e can + infinitivo (1336 ocorrências) atestam o valor modal 
médio provável a suas proposições. Os excertos abaixo revelam esse valor modal em relação às ideias de reduzir a eficácia dos cultivares (can reduce) e de refletir uma utilidade oculta (may reflect). Os operadores modais may e can, como elementos gramaticais, codificam tanto a fonte de conhecimento como a atitude do escritor acerca do grau de convicção / segurança que ele tem na confiabilidade do conhecimento exposto.

Moreover, transgene expression levels in Chinese cultivars generally decline over the growing season, which can reduce the efficacy of transgenic cultivars against bollworms (Wan et al. 2005). Thus, the use of transgenic cotton did not completely eliminate the need to spray for bollworms.

As explained above, there is a good reason to situate conventional agricultural activities beneath this benchmark. So, there will be a distance from the benchmark Dcon, which stands for a return-oriented improvement margin. The distance to reach the efficient return benchmark may reflect a hidden utility attached to farming.

Outra categoria, o adjunto de modo, como a segunda a ser estudada, é entendida como o recurso linguístico que proporciona ao escritor inserir seu julgamento de probabilidade às proposições. A classificação que prevalece, em ambas as línguas, é a intensificação/minimização, havendo uma maior frequência, claramente visível, de somente com 188 ocorrências em português e only com 779 ocorrências em inglês. Especificamente, tanto a palavra somente em português quanto only em inglês apontam restrições, ou, em outras palavras, revelam a avaliação do autor ante as evidências descritas, conforme discutido por Martin e White (2005). Os autores destacam que essa categoria oferece um sistema de opções que descreve como os escritores aumentam ou diminuem a força de suas proposições para, assim, enquadrá-las na categoria semântica que favoreça seus significados.

Oferecemos, abaixo, excertos ilustrativos dos intensificadores / minimizadores somente, em português, e only, em inglês, que reforçam a relação semântica contextual, enfatizando, no primeiro exemplo, em português, que o experimento ocorreu com apenas 500 e não com 5.000 ovos (somente com 500 ovos) e no segundo exemplo, em inglês, que o escritor restringe somente aos dois tipos de forragens: o milho e o painço japonês (Maize and Japanese millet were the only forages). 
A tendência de aumento da atividade da redutase do nitrato e de clorofila é concordante com o aumento da fotossíntese, pois a incorporação de nitrogênio em aminoácido é dependente da disponibilidade de estruturas de carbono (açúcares produzidos na fotossíntese). Entretanto, o conteúdo de carboidratos solúveis aumentou em 'IAC-20' com 500 e 5.000 ovos, não ocorrendo o mesmo com 'Acala', para a qual houve elevação somente com 500 ovos. O baixo valor em 'Acala' que recebeu 5.000 ovos seria resultado da distribuição preferencial para as raízes, como sugerido acima.

Maize and Japanese millet were the only forages to exhibit a decrease $(\mathrm{P}<0.05)$ for $\mathrm{I} 3$ compared to $\mathrm{I} 1$ in summer with up to $32 \%$ for maize, while in the autumn there was a decline in WUEt for forage radish in year 2, and sorghum in year 3. An increase in WUEt of the sorghum deficit irrigation treatments compared to the I1 in the autumn of year 2 was associated with greater incidence of northern leaf blight (Exserohilum turcicu) in the I1.

Ademais, parece evidente que é no estabelecimento da função interpessoal da linguagem, que os escritores/falantes, ao mesmo tempo, que organizam a mensagem, definem seus papéis e escolhem marcar implícita ou explicitamente seu enunciado com valores modais das diversas categorias. Na modalização, o falante/escritor pontua, um maior ou menor grau de certeza à validade de uma proposição. Já na modulação, o falante/escritor exerce um maior ou menor grau de pressão sobre o ouvinte/leitor para que execute uma ordem.

Constatamos três valores modais - Alto, Médio, Baixo - que englobam as realizações de Certeza, Probabilidade e Possibilidade. Cabe ressaltar, aqui, que esses valores manifestam o grau de comprometimento do falante com a proposição expressa e que Halliday (2004: 614) pontua que esses dados retratam áreas em uma escala e não categorias estanques e absolutas, porque 'há um re-alinhamento na concretização da relação entre a semântica e a gramática'.

Para a análise dos valores modais, identificamos padrões de realização, quantificados na Tabela 2, que nos revelam que o valor modal de maior frequência é o Médio que ressalta o valor provável, através de operadores modais (pode; may, can) e de adjuntos de modo (provavelmente; probably; usualmente; usually) tanto em português quanto em inglês. 
Como os operadores modais pode, can e may já foram exemplificados anteriormente, apresentaremos excertos dos elementos (provavelmente, probably; usualmente e usually) que compõem o valor modal Médio de maior frequência em ambas as línguas. Cabe evidenciar que o adjunto de modo provavelmente / probably revela o julgamento do escritor em relação à proposição enquanto o adjunto usualmente / usually além de expor um julgamento, envolve uma gradação entre o positivo e o negativo (Martin, Mathiessen e Painter 2010:71).

Os dois primeiros excertos, abaixo, exemplificam o uso do valor modal médio em português: provavelmente e usualmente, enquanto os dois seguintes exemplificam o valor modal em inglês: probably e usually.

Diferenças na composição química das sementes de milho-doce em relação aos demais milhos, provavelmente, contribuem para a menor tolerância ao atraso na colheita.

Os fungos de campo usualmente permanecem quiescentes durante o armazenamento da semente. Já os de armazenamento, como o nome diz, afetam as sementes armazenadas, pois são capazes de crescer sob condições relativamente secas, onde os fungos de campo não conseguem crescer.

The reduction under no-tillage for sugar beets is very substantial, making it economically unviable. This is probably mainly due to the importance of correct seed placement for the growth of sugar beets. Root systems of mature cereal crops usually possess RLDs in the topsoil far in excess of that required for the efficient uptake of water and nitrate ([Gregory et al., 1978a], [Barraclough and Leigh, 1984] and [Hoad et al., 2001]). However, limitation by RLD may occur in the sub-soil

Expomos, abaixo, uma tabela que resume e identifica os valores dos operadores modais e de adjuntos de modo: 
Tabela 2: Valores modais: Alto: 'Certo', Médio: Provável, e Baixo: 'Possível'

\begin{tabular}{|c|c|c|}
\hline Alto & Ocorrências & $\%$ \\
\hline deve / must & $235 / 126$ & $69 \% / 61 \%$ \\
\hline certamente / certainly & $19 / 20$ & $6 \% / 10 \%$ \\
\hline sempre / always & $86 / 61$ & $25 \% / 29 \%$ \\
\hline Total & $340 / 207$ & $100 \% / 100 \%$ \\
\hline Médio & Ocorrências & $\%$ \\
\hline pode / may & $1008 / 1341$ & $88,96 \% / 46 \%$ \\
\hline / can & $0 / 1336$ & $0 \% / 45 \%$ \\
\hline provavelmente / probably & $115 / 139$ & $10,15 \% / 5 \%$ \\
\hline usualmente / usually & $10 / 122$ & $0,88 \% / 4 \%$ \\
\hline Total & 1133 / 2938 & $100 \% / 100 \%$ \\
\hline Baixo & Ocorrências & $\%$ \\
\hline poderia / could & $54 / 630$ & $46,95 \% / 92 \%$ \\
\hline possivelmente / possibly & $69 / 53$ & $69 \% / 8 \%$ \\
\hline algumas vezes / sometime & $2 / 1$ & $1,74 \% / 1 \%$ \\
\hline Total & $115 / 684$ & $100 \% / 100 \%$ \\
\hline
\end{tabular}

Os adjuntos de comentário, como a terceira categoria a ser estudada, revelam uma ocorrência menor tanto em português quanto em inglês. Há vários tipos de adjuntos não realizados nos dados em ambas as línguas - constatação/revelação, quão aceitável/recomendável, quão constante/recorrente. Observa-se que houve um uso muito baixo de realmente/really, adjuntos de comentário assertivos. A maior incidência ocorre nos adjuntos de "quão válido/importante", notadamente com o uso de geralmente com 23 ocorrências e generally com 15 ocorrências. Raras, ainda, são as ocorrências em português de claramente (2); certamente (5) e obviamente (2). Seus correspondentes em inglês, no entanto, são realizados com maior: obviously com 15 ocorrências e as expected com 21 ocorrências. 
Destacamos, na tabela abaixo, as ocorrências verificadas com os adjuntos de comentário geralmente/generally em ambas as línguas e obviously/as expected somente em inglês.

Tabela 3: Adjuntos de comentário

\begin{tabular}{|l|c|c|c|}
\hline \multicolumn{1}{|c|}{ Adjuntos de Comentário } & & Ocorrências & $\%$ \\
\hline constatação/revelação & francamente / frankly & $0 / 0$ & $0 \% / 0$ \\
\hline assertivo & honestamente / honestly & $0 / 0$ & $0 \% / 0$ \\
& realmente / really & $4 / 0$ & $12,5 \% / 0 \%$ \\
\hline quão aceitável/recomendável & felizmente / luckily & $0 / 0$ & $0 \% / 0 \%$ \\
& esperançosamente / hopefully & $0 / 0$ & $0 \% / 0 \%$ \\
\hline quão constante/recorrente & tentatively / tentatively & $0 / 0$ & $0 \% / 0 \%$ \\
& provisoriamente / provisionally & $0 / 0$ & $0 \% / 0 \%$ \\
\hline quão válido/importante & geralmente falando / broadly speaking & $0 / 0$ & $0 \% / 0 \%$ \\
& geralmete falando / generally speaking & $0 / 2$ & $0 \% / 0,35 \%$ \\
& geralmente / generally & $23 / 19$ & $71,875 \% / 33,33 \%$ \\
& claramente / clearly & $2 / 11$ & $6,25 \% / 19,29 \%$ \\
& certamente / certainly & $5 / 3$ & $15,625 \% / 5,26 \%$ \\
\hline quão prudente/sensato & obviamente / obviously & $2 / 15$ & $6,25 \% / 26,31 \%$ \\
\hline como esperado & Compreensivelmente / understandbly & $0 / 0$ & $0 \% / 0 \%$ \\
& Sabiamente / wisely & $0 / 1$ & $0 \% / 1,754 \%$ \\
\hline \multicolumn{1}{|c|}{ TOTAL } & como esperado / as expected & $5 / 21$ & $15,625 \% / 36,84 \%$ \\
\hline & Surpreendentemente / amazingly & $0 / 0$ & $0 \% / 0 \%$ \\
\hline & & $32 / 57$ & $100 \% / 100 \%$ \\
\hline
\end{tabular}

Finalmente, as metáforas de modalidade, como a quarta categoria, evidenciam a voz textual que se posiciona com relação a outras vozes e outras posições no discurso. Estas expressões corroboram com o propósito comunicativo dos falantes/escritores que é de estabelecer uma avaliação positiva ou negativa dos acontecimentos em pauta sem um comprometimento pessoal dos mesmos sobre as proposições expressas (Martin e White 2005). 
A tabela, abaixo, ilustra o valor modal de maior frequência das metáforas de modalidade.

Tabela 4: Valores modais das metáforas de modalidade: Alto: 'Certo', Médio: Provável, e Baixo: 'Possível'

\begin{tabular}{|c|c|c|c|}
\hline Valor modal & & Ocorrências & $\%$ \\
\hline Baixo & Imagino / I reckon..., I guess... & $0 / 0$ & $0 \% / 0 \%$ \\
\hline Total & & $0 / 0$ & $100 \% / 100 \%$ \\
\hline Médio & $\begin{array}{l}\text { Eu acho que / I think that } \\
\text { Eu suponho que / I suppose... } \\
\text { Leva a crer/...lead us to think./lead one to think... } \\
\text { É possível que / It is possible to/that/ } \\
\text { É provável que / It is probable that }\end{array}$ & $\begin{array}{c}4 / 0 \\
0 / 0 \\
2 / 1 \\
15 / 303 \\
3 / 8\end{array}$ & $\begin{array}{c}16,66 \% / 0 \% \\
0 \% / 05 \\
8,33 \% / 0,32 \% \\
62,5 \% / 97,11 \% \\
12,5 \% / 2,56 \%\end{array}$ \\
\hline Total & & $24 / 312$ & $100 \% / 100 \%$ \\
\hline Alto & $\begin{array}{c}\text { Eu tenho certeza / I'm sure } \\
\text { Tenha certeza / make sure } \\
\text { Esteja certo / to be sure } \\
\text { Tenha certeza / certain (make certain) that } \\
\text { Certeza / certainty } \\
\text { É certo que / It is certain }\end{array}$ & $\begin{array}{l}4 / 0 \\
0 / 4 \\
0 / 4 \\
0 / 96 \\
6 / 6 \\
0 / 0\end{array}$ & $\begin{array}{c}40,0 \% / 0 \% \\
0 \% / 3,63 \% \\
0 \% / 3,63 \% \\
0 \% / 87,27 \% \\
60 \% / 5,454 \% \\
0 \% / 0 \%\end{array}$ \\
\hline Total & & $10 / 110$ & $100 \% / 100 \%$ \\
\hline
\end{tabular}

Os autores Martin, Mathiessen e Painter (2010: 68) pontuam, em suas pesquisas, que a metáfora de modalidade de maior frequência é it is possible that, de valor modal médio. Não obstante, em nosso estudo, a metáfora de modalidade é possivel que e it is possible that obtiveram maior frequência em ambas as línguas: é possível que com 15 ocorrências em português e it is possible that com 303 ocorrências em inglês. Os dados corroboram a uma evidência que os escritores se servem de uma formulação objetiva para que nenhuma orientação atitudinal explícita seja fornecida sobre a proposição em questão a fim de distanciar a avaliação do escritor.

Justificativa, também, confirmada por Martin e White (2005) que dizem que os escritores utilizam-se da metáfora de modalidade para atenuar suas declarações sobre as investigações como provável indicativo de exímio de responsabilidade quanto as suas percepções e por reconhecerem-se e acomodarem-se com o papel de menor poder em eventos comunicativos. Vejamos, abaixo, excertos da metáfora de 
modalidade de valor modal médio de maior frequência em português (é possivel que) e em inglês (it is possible that).

De acordo com Esau (1965), as folhas desenvolvidas sob a ação da luz solar direta são menores, porém mais espessas e apresentam tecido paliçádico mais diferenciado do que as folhas que se desenvolvem à sombra. No entanto, é possivel que o tecido paliçádico das folhas de Ananas comosus var. erectifolius a pleno sol não tenham seguido esse padrão de diferenciação.

Decreases in soil gravimetric water content observed at the PJF and DSC locations with the thinning treatment are opposite of what may be expected. With decreased wheat biomass, it would be expected that increased soil gravimetric water content would be present, due to reduced wheat transpiration. However, it is possible that in those cases, the thinning treatment resulted in increased soil surface evaporation due to reduced shading of the soil by the crop canopy.

Conforme pode-se observar nos excertos acima, há alta similaridade nas seleções de modalidade em ambas as línguas analisadas. No que concerne o português, o operador modal de modalização mais frequente é o pode, enquanto em inglês a maior incidência é de may e can. Nas duas línguas: (a) há maior uso de modalização que de modulação, (b) o grau predominante de probabilidade é o médio.

\section{Reflexões finais}

Em nosso trabalho como professoras de inglês para fins específicos na graduação e pós-graduação em cursos de ciências agrárias, vemos como crucial conhecermos o discurso científico da área para que possamos desenvolver nos estudantes a compreensão do discurso alvo e como seus significados são construídos por meio de escolhas lexicais e gramaticais. Para tanto, julgamos necessário irmos além da mera familiaridade assistemática com o gênero disciplinar e, juntando-nos a um grupo maior de pesquisadores que compartilha com a mesma visão, nos propusemos a analisar padrões gramaticais de artigos científicos das ciências agrárias para podermos chegar a descrições tipológicas dentro do mesmo gênero e aporte teórico (a lingüística sistêmico-funcional) entre os sistemas particulares das línguas em estudo. 
Nesse artigo, atentamos especificamente para os padrões de modalidade usados tanto na língua materna dos envolvidos no processo de ensino-aprendizagem, quanto a língua inglesa, a meta da instrução.

Lançando mão dos aportes teóricos oferecidos pela LSF - principalmente por serem esses os que possibilitam uma base contextual para se analisar os significados resultantes da tessitura da linguagem - e fazendo uso de um programa adequado a finalidade almejada, categorizamos, analisamos e comparamos as ocorrências de modalidade em artigos científicos de ciências agrárias publicados tanto em português quanto em inglês.

Em função das similitudes encontradas em ambas as línguas, inferimos que o processo de ensino-aprendizagem pode ser iniciado com textos em português para o desenvolvimento de familiarização com o gênero por parte dos estudantes. A partir daí, poder-se-á igualmente desenvolver uma conscientização da relação entre escolhas lingüísticas e construção de significados no discurso. Com isso, envolve-se o estudante na análise lingüística do texto alvo, o que entendemos benéfico não somente para propósitos de leitura, quanto de redação do cientista em formação, pois que ele, assim, entenderá que gramática e léxico são moldados segundo a intenção comunicativa do escritor. Ressalta-se, portanto, o papel mediador da linguagem na construção do discurso, ou seja, as escolhas feitas pelo escritor/pesquisador evidenciarão a realidade projetada.

Ancorado na Linguística Sistêmico-funcional, esse estudo, portanto, reafirma a contribuição da abordagem como ferramenta para mapear e analisar as características lexicais e gramaticais mais freqüentes nos artigos científicos de ciências agrárias, pois que oferece uma teoria de linguagem orientada para os propósitos do "consumidor".

Cabe, nesse momento, ressaltar algumas ponderações feitas por Halliday (2004:147-150). Uma é que o autor supracitado diz que é o julgamento do falante/escritor que situa a proposição em uma escala de maior ou menor certeza, ou seja, é através do recurso sistêmico que o falante/escritor aponta o grau de credibilidade que afere às proposições sobre as coisas do mundo. E acrescenta que 'as metáforas estão presentes no discurso como uma propriedade essencial da linguagem humana'. 
E Webster acrescenta no prefácio do livro de Halliday: A linguagem da Ciência (2004:xv):

'E Deus disse... Em uma frase, e o mundo veio a existir. A frase que deu origem a criação do universo, como relatado no Gênesis, espelha o nosso uso da linguagem para construir a realidade, e transformar experiência em significado. Esta é a força geradora de realidade da gramática, que nos capacita definir 'a experiência básica de sermos humanos' 1 .

Acrescentaríamos à citação: levando em consideração todas suas múltiplas tonalidades, realizadas por meio da paleta modalidade.

Recebido em outubro de 2012 Aprovado em novembro de 2013 E-mails: taniaromero@dch.ufla.br normajoseph@dch.ufla.br

\section{Referências bibliográficas}

Barbara, Leila \& MACÊDO, Célia Maria de Macêdo. 2011. Processos verbais em artigos acadêmicos: padrões de realização da mensagem. In: Leila Barbara; Estela Moyano. (Org.). Textos e Linguagem acadêmica: explorações sistêmicas funcionais em espanhol e português. São Paulo/Campinas: Mercado de Letras: 213-231.

Caffarel, A.; MARTIN, J. R.; MATTHiESSEN, C. M. I. M. 2004. Introduction: systemic functional typology. In: ( org.)

Language Typology: a functional perspective. Amsterdam: John Benjamins.

Christie, Francis. 2005. Language Education in the Primary Years. Sydney: University of New South Wales Press Ltd.

EgGINS, Suzanne. 1994. An Introduction to Systemic Functional Linguistics. London: Pinter Publishers Ltd.

1. And God said... With an utterance, the world came into existence. The causal origin of the universe, as told in Genesis, mirrors our own use of language to construe reality, and transform experience into meaning. Such is the reality-generating power of grammar, that it enables us to define 'the basic experience of being human'. 
Gebhard, Meg. 2010. Teacher Education in Changing Times: a systemic functional linguistics (SFL) Perspective. TESOL Quarterly, 44/4.

HaLLidAY, M.A.K. 1994. An Introduction to Functional Grammar. London: Edward Arnold.

Halliday, Michael Alexander Kirkwood \& MATHIESSEN, Christian. 2004. An Introduction to Functional Grammar. London: Edward Arnold.

. 2004. Language of Science. Edited by Jonathan, J, Webster. Great Britain: Continuum.

Martin, James \& WHITE, Peter. 2005. The Language of Evaluation. Palgrave Macmillan: USA.

Martin, James; MATHIESSEN, Christian \& PAINTER, Clare. Deploying Functional Grammar. The Commercial Press: Beijing, 2010.

Martin, James \& ROSE, David. 2005. Working with Discourse: Meaning beyond the Clause. Continuum: London.

MONTEMAYOR-Borsinger, Ann. 2009. Working with disciplinary discourses in the light of systemic functional theory. D.E.L.T.A. 25/1: 131-154.

NInIN, Maria Otília Guimarães e ROMERO, Tania Regina de Souza. 2008. Linguística Sistêmico-Funcional como Instrumento na Educação. São Paulo/São Carlos: Pedro e João Editores.

Romero, Tania Regina de Souza. 2004. Gramática e construção de significados. Claritas, 10/1: 7-26, São Paulo.

Thомpson, G. 1996. Introducing Functional Grammar. London: Arnold Publishers.

Thompson, G. 2009. Comunicação pessoal durante o 36th International Systemic Functional Congress, Beijing.

VIAN JR., Orlando e IKEDA, Sumiko Nishitani. 2009. O ensino gênero resenha pela abordagem sistêmico-funcional na formação de professores. Linguagem \& Ensino, 12/1: 13-32. Rio Grande do Sul/ Pelotas.

VIAN, JR, Orlando; SOUZA, Anderson Alves e ALMEIDA, Fabíola Sartin Dutra Parreira. 2011. A linguagem da avaliação em língua portuguesa: estudos sistêmico-funcionais com base no sistema de avaliatividade. São Paulo/ São Carlos: Pedro \& João Editores.

Webster, Jonathan J. 2007. Preface. In: The Language of Science. London: Continuum. 